\title{
A meta-analysis of efficacy and safety of PDE5 inhibitors in the treatment of ureteral stent-related symptoms
}

\author{
Dongxu Zhang ${ }^{1 \#}$, Kai Sun ${ }^{1 \#}$, Tianqi Wang ${ }^{1}$, Gang Wu ${ }^{1}$, Jipeng Wang ${ }^{1}$, Jitao Wu ${ }^{1}$, Jian Ma ${ }^{1}$, \\ Yuanshan Cui ${ }^{1,2}$ \\ ${ }^{1}$ Department of Urology, Yantai Yuhuangding Hospital, Qingdao University, Yantai, China; ${ }^{2}$ Department of Urology, Beijing Tiantan Hospital, \\ Capital Medical University, Beijing, China \\ Contributions: (I) Conception and design: Y Cui, J Ma; (II) Administrative support: Y Cui, J Wu; (III) Provision of study materials or patients: D \\ Zhang, T Wang, G Wu; (IV) Collection and assembly of data: D Zhang, K Sun, J Wang; (V) Data analysis and interpretation: D Zhang, K Sun, J \\ $\mathrm{Wu}$; (VI) Manuscript writing: All authors; (VII) Final approval of manuscript: All authors. \\ \#These authors contributed equally to this work. \\ Correspondence to: Yuanshan Cui; Jian Ma. Department of Urology, Yantai Yuhuangding Hospital, Qingdao University, No. 20 East Yuhuangding \\ Road, Yantai, China. Email: 978946700@qq.com; jma1980@126.com.
}

Background In recent years, phosphodiesterase type 5 (PDE5) inhibitors have been proposed for relieving the ureteral stent-related symptoms. We conducted a meta-analysis to assess the efficacy and safety of PDE5 inhibitors in the treatment of ureteral stent-related symptoms.

Methods: Randomized controlled trials (RCTs) that reported on the effectiveness of PDE5 inhibitors on ureteral stent-related symptoms were identified and collected from Medline, Embase, and Cochrane Library databases.

Results: Four RCTs involving 352 patients were included. Following treatment with PDE5 inhibitors for 1 week, significant improvement of urinary symptoms $(\mathrm{P}<0.00001)$ and sexual health $(\mathrm{P}=0.04)$ was observed in the PDE5 inhibitors group. After 3 weeks, we found that PDE5 inhibitors were effective in relieving urinary symptoms [mean difference (MD): $-11.94,95 \%$ confidence interval (CI): -22.58 to $-1.3, \mathrm{P}=0.03$ ], body pain (MD: $-5.38,95 \% \mathrm{CI}:-9.35$ to $-1.41, \mathrm{P}=0.008$ ), and improving sexual health (MD: $-4.13,95 \% \mathrm{CI}$ : -5.07 to $-3.19, \mathrm{P}<0.00001$ ), general health (MD: $-3.92,95 \% \mathrm{CI}:-5.76$ to $-2.08, \mathrm{P}<0.0001$ ), and additional health (MD: $-2.21,95 \% \mathrm{CI}:-4.03$ to $-0.40, \mathrm{P}=0.02$ ). With regards to work performance (MD: $-2.25,95 \%$ CI: -5.13 to $-0.62, \mathrm{P}=0.12$ ), no significant differences were observed between the PDE5 inhibitors group and the placebo group. In terms of safety, there were no significant differences between these two groups in the incidence of gastrointestinal [odds ratio (OR): $1.25,95 \%$ CI: 0.51 to 3.04, $\mathrm{P}=0.63$ ], or respiratory (OR: 1.48, 95\% CI: 0.50 to $4.44, \mathrm{P}=0.48$ ) complications.

Conclusions: PDE5 inhibitors were effective in relieving symptoms of patients undergoing ureteral stent placement, and do not increase the risk of complications.

Keywords: Meta-analysis; phosphodiesterase type 5 inhibitors (PDE5 inhibitors); ureteral stent; urinary symptom; randomized controlled trial (RCT)

Submitted Apr 29, 2020. Accepted for publication Aug 10, 2020.

doi: 10.21037/apm-20-1100

View this article at: http://dx.doi.org/10.21037/apm-20-1100

^ ORCID: 0000-0003-3649-9686. 


\section{Introduction}

First described by Zimskind et al. (1), ureteral stents have become increasingly crucial in urological surgery. A ureteral stent is a device that is inserted into the ureter to prevent obstruction of the urinary tract and allow urine to drain from the kidney to the bladder (2,3). Despite its significant role, associated complications and patient morbidities have been considered primary health concerns (4). More than $80 \%$ of patients experience stent-related symptoms, including sexual dysfunction, hematuria, and reduced work capacity (5-7). Some studies are indicating that the causes of these symptoms may be associated with stent materials, length, and position (8-11). To assess the impact and extent of stent-related symptoms on quality of life, Joshi et al. proposed a Ureteral Stent Symptom Questionnaire (USSQ) $(7,12)$.

Numerous medications have been used to relieve ureteral stent-related symptoms, including alpha-blockers, anticholinergics, and analgesics (6,13-16). More recently, phosphodiesterase type 5 (PDE5) inhibitors (such as Tadalafil, Sildenafil, and Vardenafil) have been increasingly utilized in clinical practice. PDE5 inhibitors are used extensively in the treatment of benign prostatic hyperplasia and erectile dysfunction (17-20), and work by increasing levels of cyclic adenosine monophosphate (cAMP) and cyclic guanosine monophosphate (cGMP) in the body, thus relaxing the ureteral smooth muscle and reducing ureteral spasm.

Our study was designed to measure the effectiveness of PDE5 inhibitors on ureteral stent-related symptoms to aid in the process of improving post-implantation outcomes for patients. We present the following article in accordance with Preferred Reporting Items for Systematic Reviews and Meta-Analyses (PRISMA) checklist (available at http:// dx.doi.org/10.21037/apm-20-1100) (21).

\section{Methods}

\section{Search strategy}

Randomized controlled trials (RCTs) that analyzed the effectiveness of PDE5 inhibitors on stent-related symptoms were retrieved from Medline, Embase, and Cochrane Library databases. The following search terms were used: PDE5 inhibitors, ureteral stent, urinary symptoms, and RCT. All articles and relevant references of included studies were retrieved and screened by two authors. Our search conditions were limited to published articles, and there were no restrictions on language or region. Disputes during the review process were referred to as the third author for approval.

\section{Inclusion criteria}

RCTs included in our meta-analysis met the following criteria: (I) the study analyzed treatment with PDE5 inhibitors; (II) full text of the study could be provided; (III) precise data could be extracted from the study, including the sample size of participants and the values of each indicator (such as the USSQ); and (IV) the study selected the USSQ as the primary outcome assessment indicator. The PRISMA flow diagram of study selection is shown in Figure 1.

\section{Quality assessment}

The quality of RCTs included in our meta-analysis was evaluated according to the Jadad Scale (22). Based on the guidelines published in the Cochrane Handbook for Systematic Reviews of Interventions V.5.1.0 (23), individual studies were classified qualitatively and graded into the following quality levels: A, studies meeting most of the quality criteria had a low risk of bias; $\mathrm{B}$, studies meeting some of the criteria had a moderate risk of bias; $\mathrm{C}$, studies meeting few criteria had a high risk of bias. All reviewers contributed to the assessment and review of the included studies, settling differences through discussion and reaching a consensus on the final result.

\section{Data extraction}

Data collected from the RCTs included: (I) the name of the first author; (II) the time of publication and the type of design; (III) the sample size of each group; (IV) the results of the studies, including the scores of USSQ (urinary symptoms score, body pain score, sexual health score, general health score, work performance score, additional health score); (V) the methods of intervention; and (VI) the stent type.

\section{Statistical and meta-analyses}

RevMan version 5.3.0 (Cochrane Collaboration, Oxford, UK) (23) was employed to assess the data. Changes in the mean score of urinary symptoms, body pain, sexual health, general health, work performance, and additional health were used to evaluate the efficacy of PDE5 inhibitors in 


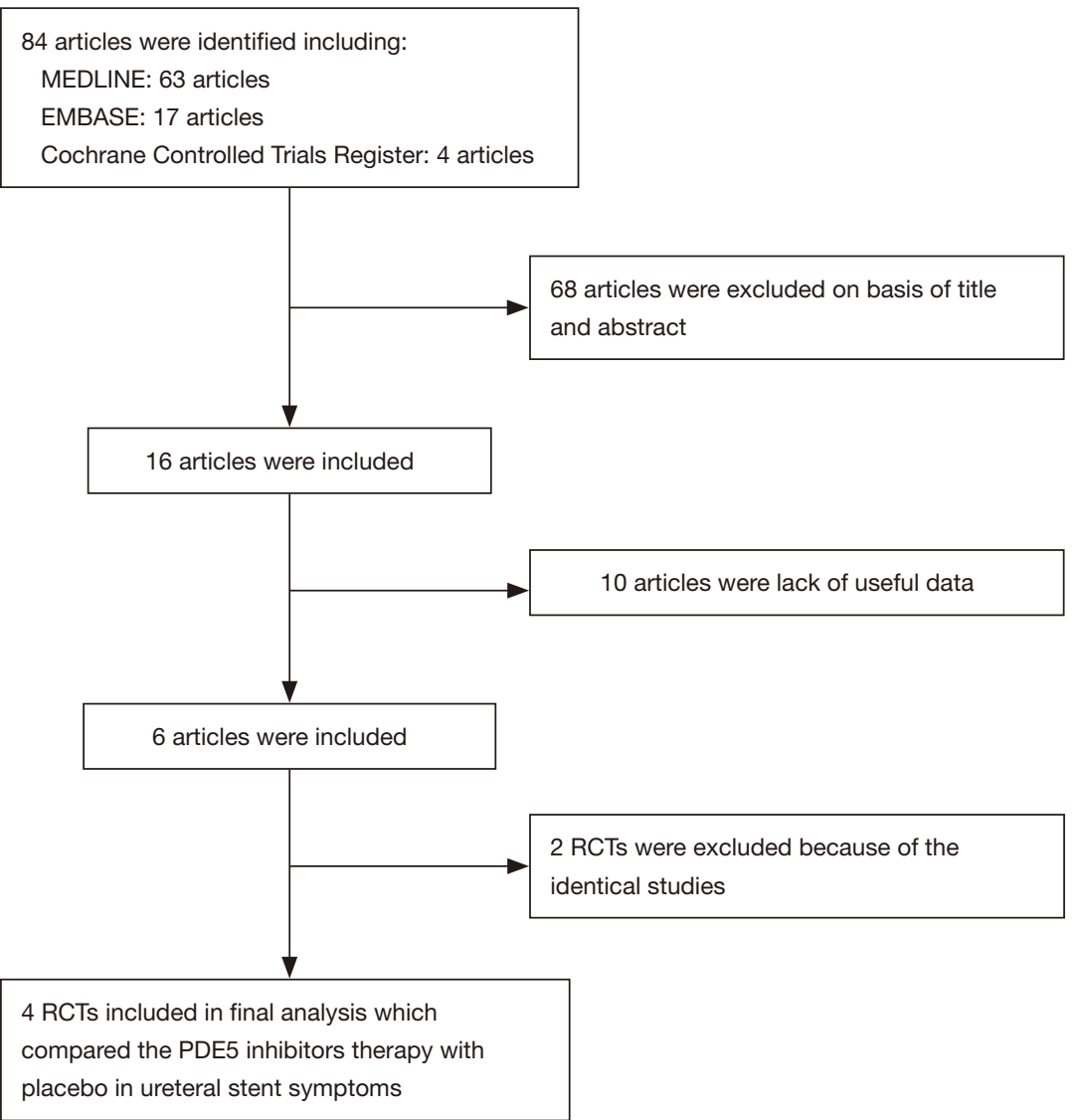

Figure 1 Flowchart of the study selection process. RCT, randomized controlled trial; PDE5, phosphodiesterase type 5.

relieving symptoms of patients undergoing stent placement. The mean difference (MD) was used to assess continuous data, and the odds ratio (OR) was used to evaluate dichotomous data to compare the outcomes between the PDE5 inhibitor group and the placebo group (23). A fixed- or random-effects model was used based on the heterogeneity of the studies. Studies with a $\mathrm{P}$ value $>0.05$ were considered homogenous, and studies with a $\mathrm{P}$ value $<0.05$ were considered heterogeneous. A fixed-effects model was employed for homogenous studies, while a randomeffects model was used for heterogeneous studies. The $\mathrm{I}^{2}$ statistic was used to test for consistency. A $\mathrm{P}$ value $<0.05$ was considered statistically significant.

\section{Results}

\section{Characteristics of individual articles}

Based on the inclusion criteria above, 84 RCTs were found in the databases searched. After reviewing the abstracts, 68 articles were removed. Of the remaining 16 articles, 10 were removed due to a lack of useful data, and another 2 were excluded due to duplication. Ultimately, four RCTs (24-27) were included in our meta-analysis. The characteristics of the included studies and patients involved are presented in Table 1.

\section{Quality of individual studies}

The included studies were double-blinded RCTs and were graded quality level A (based on the quality criteria above). Only one study (27) showed an intention-to-treat (ITT) analysis. The quality of the individual studies is shown in Table 2.

\section{Efficacy}

We analyzed the differences in the mean score of each domain of the USSQ in order to identify the efficacy 
Table 1 Study and patient characteristics

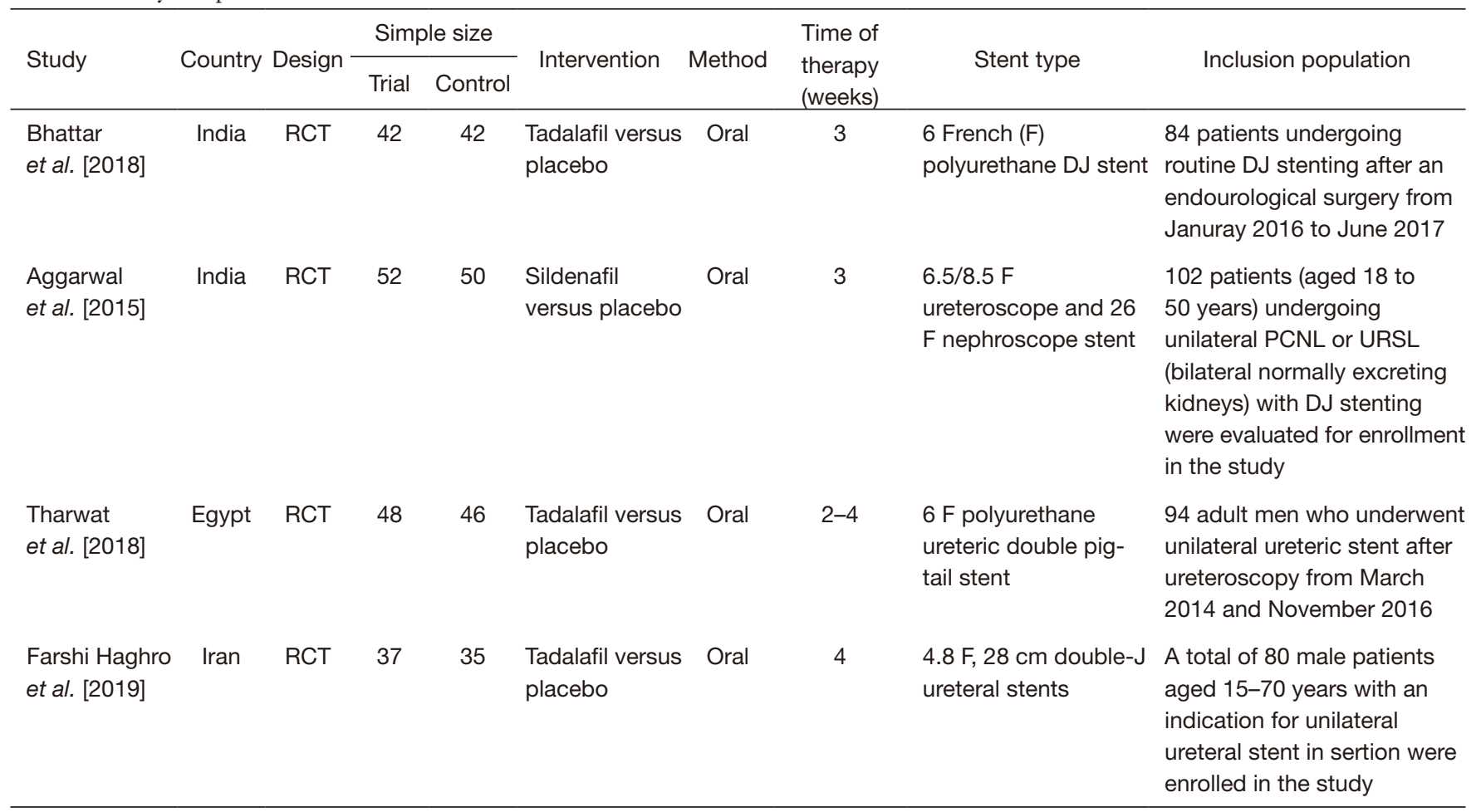

RCT, randomized controlled trial; PCNL, percutaneous nephrolithotomy; URSL, ureteroscopic lithotripsy.

Table 2 Quality assessment of individual study

\begin{tabular}{|c|c|c|c|c|c|c|c|c|}
\hline Study & $\begin{array}{c}\text { Allocation sequence } \\
\text { generation }\end{array}$ & $\begin{array}{c}\text { Allocation } \\
\text { concealment }\end{array}$ & Blinding & $\begin{array}{l}\text { Loss to } \\
\text { follow-up }\end{array}$ & $\begin{array}{l}\text { Calculation of } \\
\text { sample size }\end{array}$ & $\begin{array}{l}\text { Statistical } \\
\text { analysis }\end{array}$ & $\begin{array}{l}\text { Level of } \\
\text { quality }\end{array}$ & $\begin{array}{c}\mathrm{ITT} \\
\text { analysis }\end{array}$ \\
\hline Bhattar et al. [2018] & A & $A$ & A & 6 & Yes & ANCOVA & A & No \\
\hline Tharwat et al. [2018] & A & A & A & 7 & Yes & ANCOVA & A & No \\
\hline
\end{tabular}

A, all quality criteria met (adequate): low risk of bias; $B$, most quality criteria met (adequate): moderate risk of bias. ITT, intention-to-treat; ANCOVA, analysis of covariance.

of treatment with PDE5 inhibitors. Also, we analyzed the differences in the USSQ at both the 1- and 3-week treatment stage.

\section{Results after 1 week of treatment with PDE5 inbibitors}

\section{Urinary symptoms score}

Two of the four RCTs included in our meta-analysis reported changes in urinary symptoms scores from 186 patients (94 treated with PDE5 inhibitors and 92 given a placebo) (Figure $2 A$ ). The MD was used to compare effect measures between the PDE5 inhibitors groups and the placebo groups. Since $\mathrm{P}>0.05$, a fixed-effects model was used to analyze the results of these two RCTs and revealed that $\mathrm{MD}$ was $-2.81,95 \%$ confidence interval $(\mathrm{CI})$ was -3.72 to $-1.90, \mathrm{I}^{2}$ was $13 \%$, and Chi-square $\left(\mathrm{Chi}^{2}\right)$ was 1.15 $(\mathrm{P}<0.00001)$. Based on these results, we concluded that PDE5 inhibitors improved urinary symptoms scores at the 1-week treatment stage.

\section{Body pain score}

Two RCTs reported body pain scores of 186 patients after 
1 week of ureteral stenting (Figure $2 B$ ). Since $\mathrm{P}>0.05$, we used a fixed-effects model and concluded that PDE5 inhibitors produce little relief in body pain at 1-week (MD: $0.43,95 \%$ CI: -0.40 to $1.26, \mathrm{I}^{2}=70 \%, \mathrm{Chi}^{2}=1.15, \mathrm{P}=0.31$ ).

\section{Sexual health score}

Two RCTs reported changes in sexual health scores from 186 patients (Figure $2 C$ ). Since $\mathrm{P}>0.05$, a fixed-effects model was used to evaluate the results, which showed that $\mathrm{MD}$ was $-0.57,95 \%$ CI was -1.13 to $-0.01, \mathrm{I}^{2}$ was $54 \%$, and $\mathrm{Chi}^{2}$ was $2.17(\mathrm{P}=0.04)$. Thus, patients experienced improved sexual health following treatment with PDE5 inhibitors for 1 week.

\section{General health score}

Since $\mathrm{P}<0.05$, a random-effects model was used to analyze the general health scores for two RCTs. Results showed a MD of -0.82 (95\% CI: -4.35 to $2.71, \mathrm{I}^{2}=91 \%, \mathrm{Chi}^{2}=10.58$, $\mathrm{P}=0.65$ ) (Figure 2D). We suggest that the effect of PDE5 inhibitors on general health was similar to that of placebo after 1 week of treatment.

\section{Work performance score}

Since $\mathrm{P}<0.05$, we utilized a random-effects model to study the effect of PDE5 inhibitors on work performance from two RCTs (Figure 2E). The pooled estimate of MD was $-0.16,95 \% \mathrm{CI}$ was -1.75 to $1.42, \mathrm{I}^{2}$ was $76 \%$, and $\mathrm{Chi}^{2}$ was $4.18(\mathrm{P}=0.84)$. The results revealed that therapy with PDE5 inhibitors exhibited similar effects on work performance as a placebo after 1 week of treatment.

\section{Additional health score}

Two RCTs involving 186 patients reported the efficacy indices of PDE 5 inhibitors on the additional health score (Figure $2 F$ ). Since $\mathrm{P}<0.05$, we utilized a randomeffects model to analyze the data. We did not find any statistically significant relationship between the two groups on additional health after 1 week of treatment with PDE5 inhibitors (MD: $-2.25,95 \%$ CI: -4.91 to $0.42, \mathrm{I}^{2}=94 \%$, $\mathrm{Chi}^{2}$ $=18.06, \mathrm{P}=0.10)$.

\section{Results after 3 weeks of treatment with PDE5 inbibitors}

\section{Urinary symptoms score}

Four RCTs involving 352 patients (179 treated with PDE5 inhibitors and 173 given a placebo) recorded the changes in urinary symptoms scores after 3 weeks of treatment (Figure $3 A$ ). Since $\mathrm{P}<0.05$, we employed a random-effects model, which reflected a MD of -11.94 (95\% CI: -22.58 to $\left.-1.3, \mathrm{I}^{2}=99 \%, \mathrm{Chi}^{2}=466.83, \mathrm{P}=0.03\right)$. The results suggest that PDE5 inhibitors showed a greater reduction in the urinary symptoms scores compared with a placebo.

\section{Body pain score}

Four RCTs involving 352 patients reported changes in body pain scores (Figure $3 B$ ). Since $\mathrm{P}<0.05$, a random-effects model was used. Results showed a reduction in body pain in the PDE5 inhibitors group compared to the placebo group after 3 weeks of treatment (MD: $-5.38,95 \%$ CI: -9.35 to $\left.-1.41, \mathrm{I}^{2}=95 \%, \mathrm{Chi}^{2}=65.81, \mathrm{P}=0.008\right)$.

\section{Sexual health score}

Four RCTs involving 352 patients reported the differences in sexual health scores (Figure 3C). Heterogeneity was found in the trials $\left(\mathrm{P}=0.004, \mathrm{I}^{2}=78 \%\right)$, and since $\mathrm{P}<0.05$, we used a random-effects model to analyze the data. Based on the results, therapy with PDE5 inhibitors was shown to improve the sexual health of patients with ureteral stents. The results of integrative data analysis indicated that MD was $-4.13,95 \%$ CI was -5.07 to -3.19 , and $\mathrm{Chi}^{2}$ was 13.35 $(\mathrm{P}<0.00001)$.

\section{General health score}

Four RCTs involving 352 patients were used to analyze general health scores (Figure $3 D$ ). Since $\mathrm{P}<0.05$, a randomeffects model was employed, and showed a MD of -3.92 (95\% CI: -5.76 to $-2.08, \mathrm{I}^{2}=88 \%, \mathrm{Chi}^{2}=24.61, \mathrm{P}<0.0001$ ). From these results, we concluded that PDE5 inhibitors had a significant benefit on general health scores after 3 weeks of treatment.

\section{Work performance score}

Four RCTs analyzed the changes in work performance scores of 352 patients (Figure $3 E$ ). Since $\mathrm{P}<0.05$, we performed a random-effects model analysis that showed MD was $-2.25,95 \%$ CI was -5.13 to $0.62, \mathrm{I}^{2}$ was $95 \%$, and $\mathrm{Chi}^{2}$ was $57.80(\mathrm{P}=0.12)$. These results reflect no significant effect on work performance after 3 weeks of therapy with PDE5 inhibitors.

\section{Additional health score}

Three RCTs reported the additional health score data of 258 patients (Figure $3 F$ ). Since $\mathrm{P}<0.05$, the RCTs were assessed using a random-effects model. The MD was -2.21 , $95 \%$ CI was -4.03 to $-0.40, \mathrm{I}^{2}$ was $89 \%$, and $\mathrm{Chi}^{2}$ was 18.54 $(\mathrm{P}=0.02)$, indicating a significantly greater reduction in the 


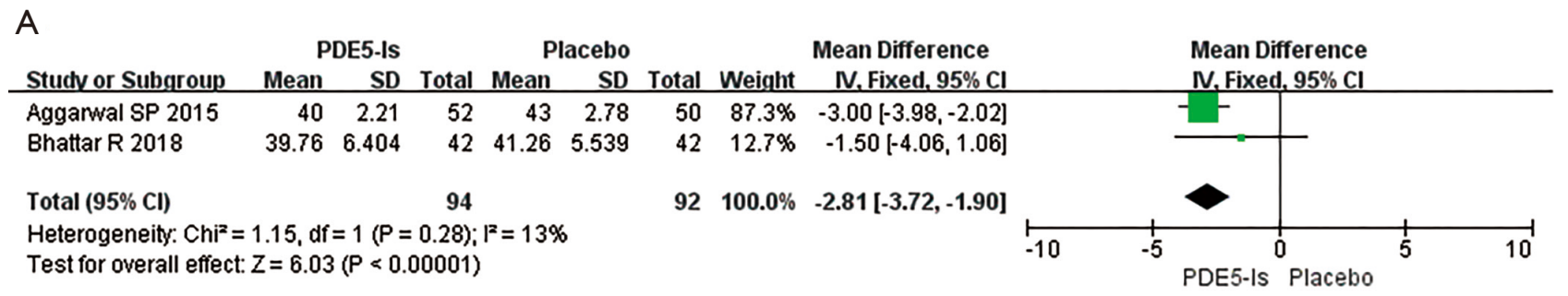

B

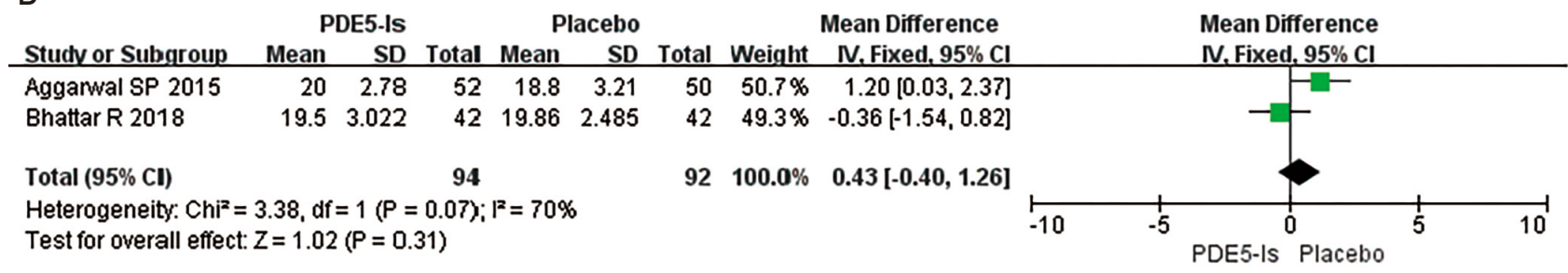

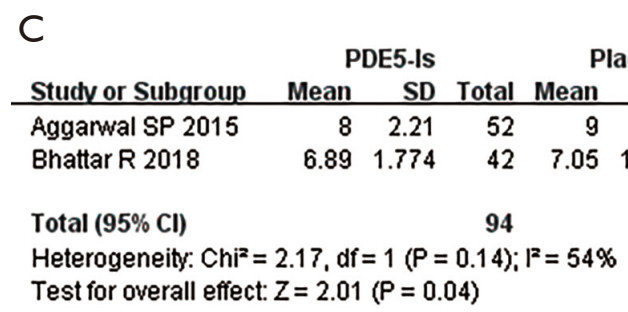

Placebo Mean Difference Mean Difference

SD Total Weight IV, Fixed, 95\% Cl I, Fixed, 95\% Cl

$50 \quad 49.1 \% \quad-1.00[-1.80,-0.20]$

$42 \quad 50.9 \% \quad-0.16[-0.94,0.62]$

$92100.0 \%-0.57[-1.13,-0.01]$

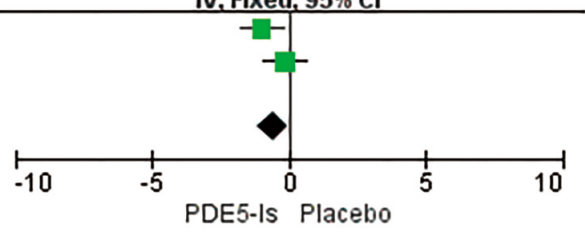

D

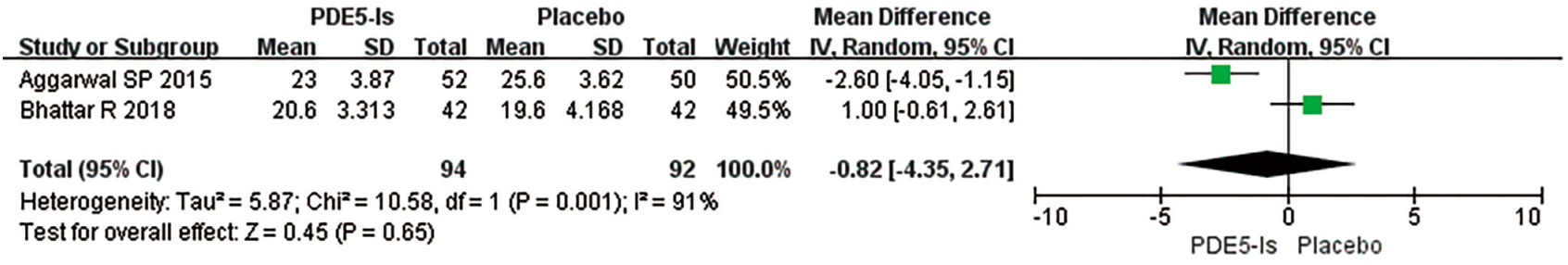

E

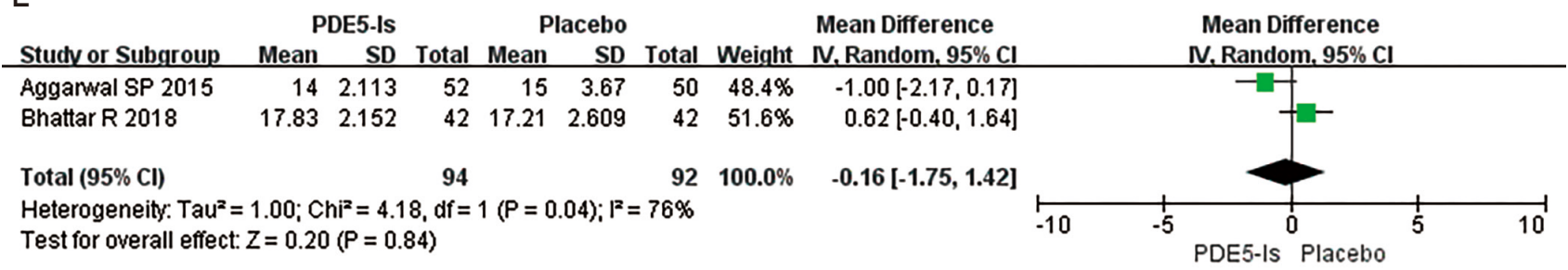

F

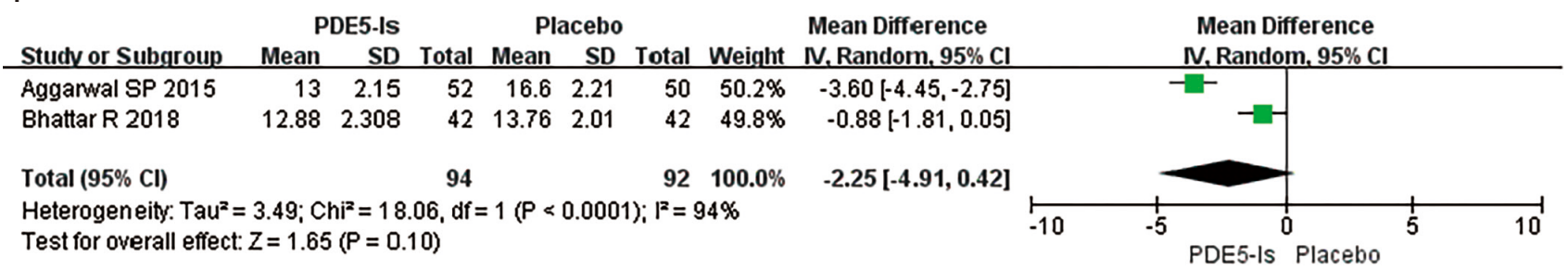

Figure 2 Forest plots showing changes between two groups after 1 week's treatment in: (A) urinary symptoms score; (B) body pain score; (C) sexual health score; (D) general health score; (E) work performance score; (F) additional health score. PDE5-Is, phosphodiesterase type 5 inhibitors; CI, confidence interval. 


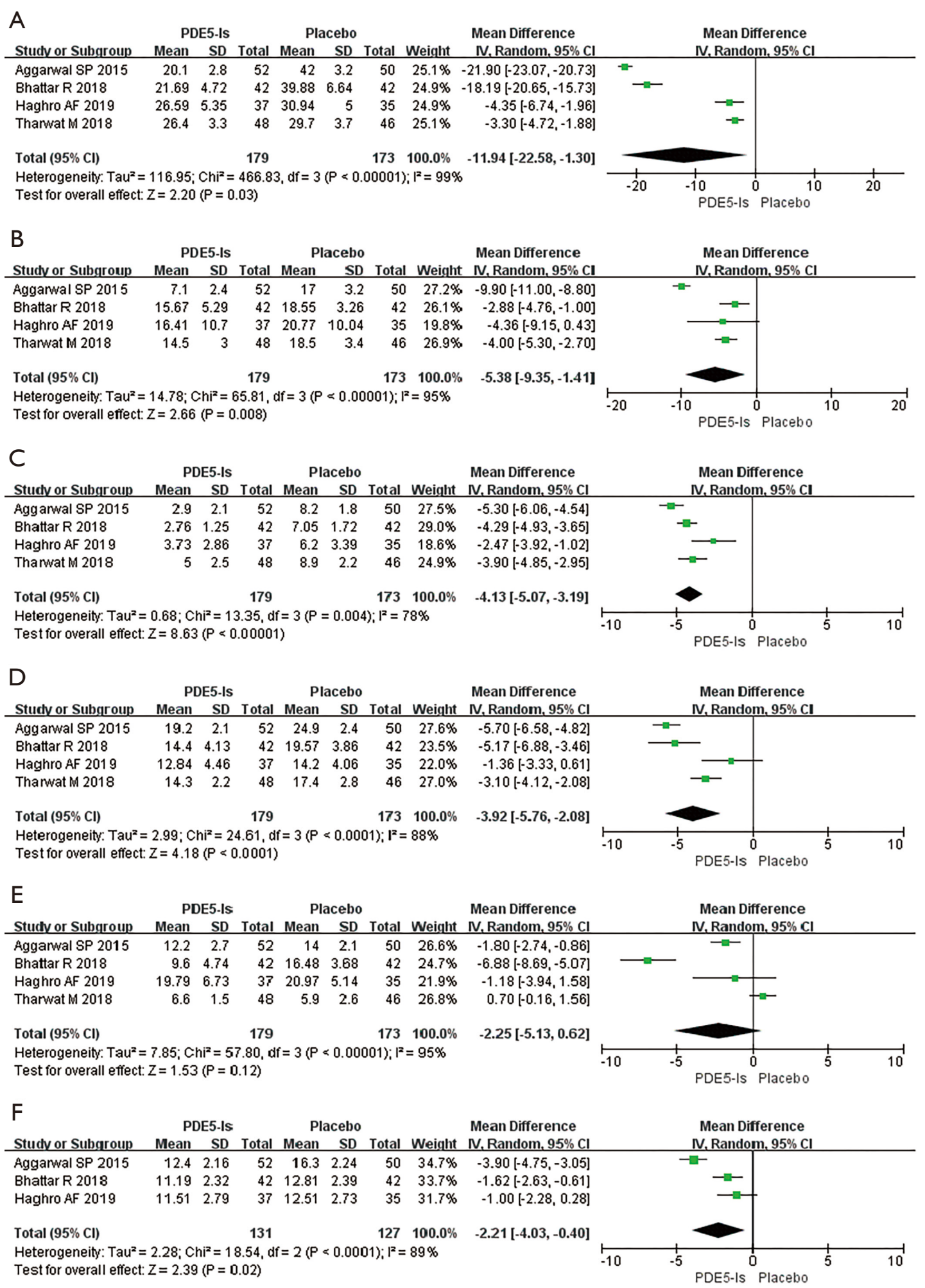

Figure 3 Forest plots showing changes between two groups after 3 weeks' treatment in: (A) urinary symptoms score; (B) body pain score; (C) sexual health score; (D) general health score; (E) work performance score; (F) additional health score. PDE5-Is, phosphodiesterase type 5 inhibitors. 
A

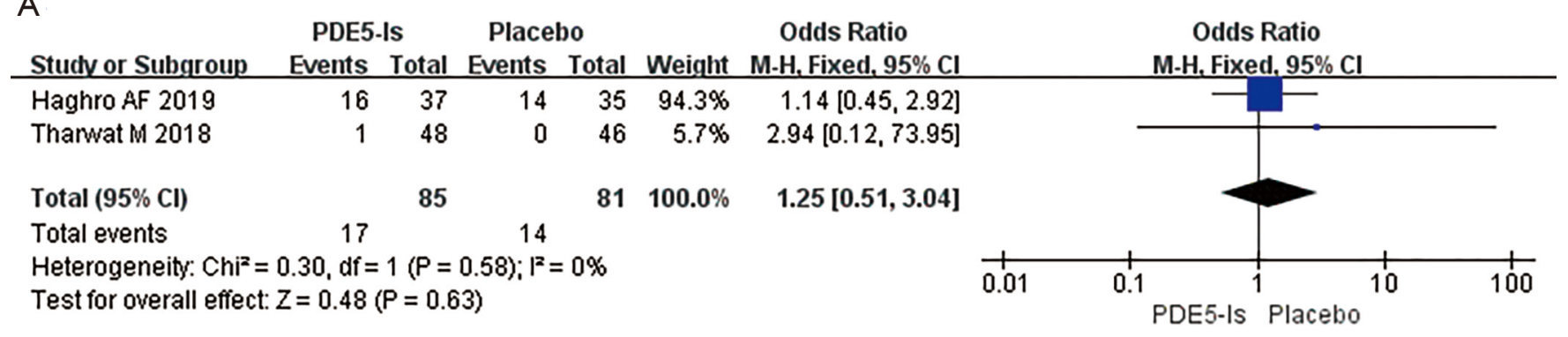

B

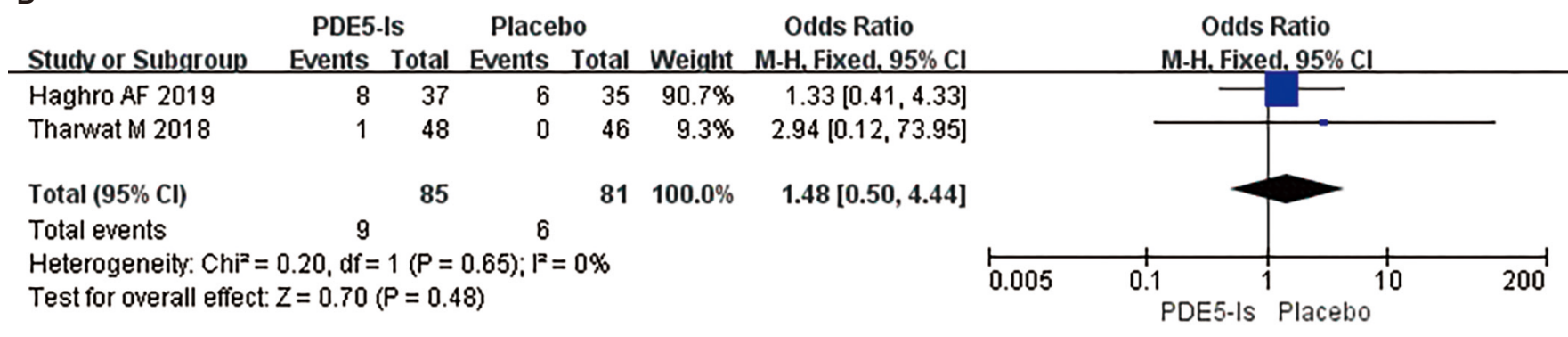

Figure 4 Forest plots showing changes between two groups after 3 weeks' treatment in: (A) gastrointestinal complications; (B) respiratory complications. PDE5-Is, phosphodiesterase type 5 inhibitors.

additional health scores after 3 weeks of treatment with PDE5 inhibitors.

\section{Safety}

\section{Gastrointestinal complications}

Two RCTs, including 166 patients (85 treated with PDE5 inhibitors and 81 given a placebo), documented the risk of gastrointestinal complications (Figure $4 A$ ). Since $\mathrm{P}>0.05$, we utilized a fixed-effects model. The OR was $1.25,95 \%$ CI was 0.51 to $3.04, \mathrm{I}^{2}$ was $0 \%$, and $\mathrm{Chi}^{2}$ was $0.30(\mathrm{P}=0.63)$, indicating no significant differences in the incidence of gastrointestinal complications between the two groups after 3 weeks.

\section{Respiratory complications}

Two RCTs analyzed the incidence of respiratory complications of 166 patients after 3 weeks of treatment with PDE5 inhibitors (Figure 4B). Since P>0.05, we used a fixed-effects model. The OR was $1.48,95 \%$ CI was 0.50 to $4.44, \mathrm{I}^{2}$ was $0 \%$, and $\mathrm{Chi}^{2}$ was $0.20(\mathrm{P}=0.48)$, indicating that there was no significant difference in the incidence of respiratory complications between the PDE5 inhibitors group and the placebo group after 3 weeks.

\section{Discussion}

Since their first clinical application, ureteral stents have become the most common method for treatment or prevention of ureteral obstruction $(1,28,29)$. The placement of a ureteral stent after kidney-stone surgery is especially effective in preventing ureteral obstruction and reducing the incidence of infection. Furthermore, the effect of ureteral stents in the treatment of ureteral injury is also significant and can help to avoid hydronephrosis. Despite its apparent advantages, urinary symptoms caused by indwelling ureteral stents should not be ignored since they can have a particularly negative impact on a patients' quality of life $(7,30,31)$. At present, the pathophysiology of these symptoms is unclear. Previous studies have suggested that stent position may be relevant to the occurrence of these symptoms (8). Lennon et al. concluded that physical stimulation by the stent is potentially responsible for related symptoms (32). Another theory suggests that smooth muscle spasm and stimulation of the stent are the underlying causes of flank pain (33).

A better understanding of the pathophysiology of stentrelated symptoms has lead to continued optimization of treatment options. Improving the design and materials of ureteral stents is critical in alleviating related symptoms (2). 
Several medications are utilized in clinical practice, most commonly alpha-blockers and anticholinergics $(6,13)$. PDE5 inhibitors (such as Tadalafil, Sildenafil, and Vardenafil) are first-line drugs for the treatment of related symptoms of benign prostatic hyperplasia. Aggarwal et al. concluded that Tadalafil is as effective as Tamsulosin in treating ureteral stent-related symptoms; however, it was more effective in improving sexual dysfunction and body pain (25). PDE5 inhibitors act by preventing the degradation of cAMP and cGMP, resulting in increased levels of these chemicals in the body, thus relaxing the ureteric smooth muscle and reducing the ureteral spasm. So, blocking PDE5 receptors may relieve stent-related symptoms. Also, Angulo et al. showed that PDE5 inhibitors enhanced the effect of alpha-1 blockers, further reducing smooth muscle contraction in the bladder and prostate (34). PDE5 inhibitors have also been shown to relieve urinary symptoms.

In order to better evaluate the symptoms of patients after ureteral stenting, Joshi et al. introduced the USSQ (12), which evaluates symptoms from the following domains: urinary symptoms, body pain, sexual health, general health, work performance, and additional health. The USSQ contains many questions regarding each of these aspects, with higher scores indicating worse stent-related symptoms (12).

Our meta-analysis included four RCTs involving 352 participants who underwent ureteral stent placement. Significant improvements in urinary symptoms and sexual health were observed after 1 week of treatment with PDE5 inhibitors. Data analysis after 3 weeks of treatment with PDE5 inhibitors indicated that the improvement in the mean score was statistically significant. The pooled results showed a significant benefit of PDE5 inhibitors in relieving urinary symptoms, body pain, sexual health, general health, and additional health. Regarding work performance, therapy with PDE5 inhibitors was similar to that of the placebo group. The lack of improvement in work performance with PDE5 inhibitors may be related to their side effects. This idea is corroborated by the findings of Farshi Haghro et al., which showed that PDE5 inhibitors might cause side effects such as priapism, headache, and hypotension, all of which can lead to poor work performance (27). Since the mean USSQ score can effectively evaluate ureteral stentrelated symptoms and quality of life after stent placement $(12,35,36)$, we can surmise that PDE5 inhibitors are effective in relieving symptoms of patients undergoing stent placement. As for safety, the incidence of gastrointestinal and respiratory complications was similar between the
PDE5 inhibitor and placebo groups.

Similarly, Farshi Haghro et al. found that the incidence of cardiovascular, neurological, and genitourinary complications with PDE5 inhibitor-therapy was comparable to placebos (27). Thus, we conclude that PDE5 inhibitors do not increase the risk of complications. The findings of this meta-analysis are significant for clinical practice and future scientific inquiry.

In order to verify the consistency of our results, participants were divided into two subgroups according to the duration of treatment (1- and 3-week treatment). By studying the differences between these subgroups, the bias caused by the half-life of the drugs could be avoided. Furthermore, while our study showed differences in the effect of PDE5 inhibitors at 1 - and 3 -week treatment stages, the curative effect will change with the duration of treatment. The pooled results indicated that urinary symptoms and sexual health improved after 1 week of treatment with PDE5 inhibitors. At the 3-week treatment stage, symptoms of body pain, general health, and additional health were alleviated. These findings provide evidence for the formulation of a reasonable clinical application protocol.

Compared with previous studies in this area (37), our meta-analysis has the following advantages. Firstly, we included more RCTs with larger overall sample size, and thus, the experimental results are more reliable. Secondly, our study analyzed both efficacy and safety, providing more comprehensive results. Thirdly, our study assessed results at both the 1- and 3-week treatment stages, thereby providing greater significance for clinical reference. Moreover, our data has been collected from RCTs, which are considered to have a low risk of bias.

Some limitations of this study should be noted. Firstly, Bhattar et al. took sexual activity as the inclusion index of patients who participated in their study, with 352 patients being included (24). However, other RCTs included in our meta-analysis did not specify the sexual activity of the included patients, and therefore, limitations may exist in our conclusions regarding the improvement in sexual function with PDE5 inhibitor therapy. Also, while additional health was chosen as an indicator for assessing stent-related symptoms in our study, none of the included RCTs reported the single score for the additional health domain. To address this, we will continue to focus on future research on the most recent RCTs.

Moreover, potential limitations may exist due to the multiple causes of stent-related urinary symptoms. Nestler et al. showed that stents with larger diameters exacerbated 
related symptoms (38). Three of the four RCTs included in our meta-analysis reported that patients involved in their studies had a 6 French $(\mathrm{F})$ polyurethane double pigtail stent (24-26), while the remaining RCT described that patients included in their study used $4.8 \mathrm{~F}$ double-J ureteral stents (27). This discrepancy may lead to a potential bias in the results. Also, the stone level may cause urinary symptoms; the RCTs included in our meta-analysis do not mention differences in urinary symptoms caused by stone location. We will pay particular attention to this in future research.

Furthermore, due to the limitations of the included RCTs, different PDE5 inhibitors (Tadalafil and Sildenafil) could not be grouped in our study, which may also lead to a bias in the results. In the future, we will continue to focus on high-quality related studies (especially RCTs), which will allow for more robust conclusions to be drawn. Finally, the limitations of the meta-analysis of randomized trials cannot be ignored. It is important to note that this meta-analysis should not be regarded as evidence for evaluating the longterm effect of PDE5 inhibitors. More RCTs are required to explore further the efficacy and safety of PDE5 inhibitors on ureteral stent-related symptoms.

\section{Conclusions}

In conclusion, PDE5 inhibitors can relieve the ureteral stent-related symptoms, and do not increase the risk of complications.

\section{Acknowledgments}

The authors acknowledge AME Editing Service for checking the language of the manuscript. The authors also thank reviewers and editors for their insightful suggestions.

Funding: This work was supported by grants from the National Nature Science Foundation of China (Nos. 81801429, 81870525), Taishan Scholars Program of Shandong Province (No. tsqn201909199).

\section{Footnote}

Reporting Checklist: The authors have completed Preferred Reporting Items for Systematic Reviews and MetaAnalyses (PRISMA) checklist. Available at http://dx.doi. org/10.21037/apm-20-1100

Peer Review File: Available at http://dx.doi.org/10.21037/ apm-20-1100

Conflicts of Interest: All authors have completed the the ICMJE uniform disclosure form (available at http://dx.doi. org/10.21037/apm-20-1100). The authors have no conflicts of interest to declare.

Etbical Statement: The authors are accountable for all aspects of the work in ensuring that questions related to the accuracy or integrity of any part of the work are appropriately investigated and resolved. This study was based on previously published studies; therefore, ethical approval and patient consent were not required.

Open Access Statement: This is an Open Access article distributed in accordance with the Creative Commons Attribution-NonCommercial-NoDerivs 4.0 International License (CC BY-NC-ND 4.0), which permits the noncommercial replication and distribution of the article with the strict proviso that no changes or edits are made and the original work is properly cited (including links to both the formal publication through the relevant DOI and the license). See: https://creativecommons.org/licenses/by-nc-nd/4.0/.

\section{References}

1. Zimskind PD, Fetter TR, Wilkerson JL. Clinical use of long-term indwelling silicone rubber ureteral splints inserted cystoscopically. J Urol 1967;97:840-4.

2. Dellis A, Joshi HB, Timoney AG, et al. Relief of stent related symptoms: review of engineering and pharmacological solutions. J Urol 2010;184:1267-72.

3. Liu Q, Liao B, Zhang R, et al. Combination therapy only shows short-term superiority over monotherapy on ureteral stent-related symptoms - outcome from a randomized controlled trial. BMC Urol 2016;16:66.

4. Irani J, Siquier J, Pirès C, et al. Symptom characteristics and the development of tolerance with time in patients with indwelling double-pigtail ureteric stents. BJU Int 1999;84:276-9.

5. Mokhtari G, Shakiba M, Ghodsi S, et al. Effect of terazosin on lower urinary tract symptoms and pain due to double-J stent: a double-blind placebo-controlled randomized clinical trial. Urol Int 2011;87:19-22.

6. Zhou L, Cai X, Li H, et al. Effects of $\alpha$-blockers, antimuscarinics, or combination therapy in relieving ureteral stent-related symptoms: a meta-analysis. J Endourol 2015;29:650-6. 
7. Joshi HB, Okeke A, Newns N, et al. Characterization of urinary symptoms in patients with ureteral stents. Urology 2002;59:511-6.

8. Giannarini G, Keeley FX Jr, Valent F, et al. Predictors of morbidity in patients with indwelling ureteric stents: results of a prospective study using the validated Ureteric Stent Symptoms Questionnaire. BJU Int 2011;107:648-54.

9. Rane A, Saleemi A, Cahill D, et al. Have stent-related symptoms anything to do with placement technique? J Endourol 2001;15:741-5.

10. Al-Kandari AM, Al-Shaiji TF, Shaaban H, et al. Effects of proximal and distal ends of double-J ureteral stent position on postprocedural symptoms and quality of life: a randomized clinical trial. J Endourol 2007;21:698-702.

11. Taguchi M, Yoshida K, Sugi M, et al. A ureteral stent crossing the bladder midline leads to worse urinary symptoms. Cent European J Urol 2017;70:412-7.

12. Joshi HB, Newns N, Stainthorpe A, et al. Ureteral Stent Symptom Questionnaire: development and validation of a multidimensional quality of life measure. J Urol 2003;169:1060-4.

13. Lamb AD, Vowler SL, Johnston R, et al. Meta-analysis showing the beneficial effect of $\alpha$-blockers on ureteric stent discomfort. BJU Int 2011;108:1894-902.

14. Koprowski C, Kim C, Modi PK, et al. Ureteral stentassociated pain: a review. J Endourol 2016;30:744-53.

15. Wang CJ, Huang SW, Chang CH. Effects of specific alpha-1A/1D blocker on lower urinary tract symptoms due to double-J stent: a prospectively randomized study. Urol Res 2009;37:147-52.

16. Kwon JK, Cho KS, Oh CK, et al. The beneficial effect of alpha-blockers for ureteral stent-related discomfort: systematic review and network meta-analysis for alfuzosin versus tamsulosin versus placebo. BMC Urol 2015;15:55.

17. Balon R, Morreale MK, Segraves RT. Prescribing of phosphodiesterase-5 inhibitors among psychiatrists. J Sex Marital Ther 2014;40:165-9.

18. Andersson KE, de Groat WC, McVary KT, et al. Tadalafil for the treatment of lower urinary tract symptoms secondary to benign prostatic hyperplasia: pathophysiology and mechanism(s) of action. Neurourol Urodyn 2011;30:292-301.

19. Chapple CR, Roehrborn CG, McVary K, et al. Effect of tadalafil on male lower urinary tract symptoms: an integrated analysis of storage and voiding international prostate symptom subscores from four randomised controlled trials. Eur Urol 2015;67:114-22.

20. Gacci M, Corona G, Salvi M, et al. A systematic review and meta-analysis on the use of phosphodiesterase 5 inhibitors alone or in combination with $\alpha$-blockers for lower urinary tract symptoms due to benign prostatic hyperplasia. Eur Urol 2012;61:994-1003.

21. Moher D, Liberati A, Tetzlaff J, et al. Preferred reporting items for systematic reviews and meta-analyses: the PRISMA statement. J Clin Epidemiol 2009;62:1006-12.

22. Jadad AR. Randomised controlled trials. London: BMJ Publishing Group, 1998.

23. DerSimonian R, Laird N. Meta-analysis in clinical trials. Control Clin Trials 1986;7:177-88.

24. Bhattar R, Tomar V, Yadav SS, et al. Comparison of safety and efficacy of silodosin, solifenacin, tadalafil and their combinations in the treatment of double-J stent- related lower urinary system symptoms: a prospective randomized trial. Turk J Urol 2018;44:228-38.

25. Aggarwal SP, Priyadarshi S, Tomar V, et al. A randomized controlled trial to compare the safety and efficacy of tadalafil and tamsulosin in relieving double $\mathrm{j}$ stent related symptoms. Adv Urol 2015;2015:592175.

26. Tharwat M, Elsaadany MM, Lashin AM, et al. A randomized controlled trial evaluating sildenafil citrate in relieving ureteral stent-related symptoms. World J Urol 2018;36:1877-81.

27. Farshi Haghro A, Hajebrahimi S, Jabbari A, et al. Efficacy of tadalafil on ureteral stent symptoms: a randomized controlled trial. Nephro-Urol Mon 2019;11:e85523.

28. Damiano R, Autorino R, Esposito C, et al. Stent positioning after ureteroscopy for urinary calculi: the question is still open. Eur Urol 2004;46:381-7; discussion 387-8.

29. Aungst MJ, Sears CL, Fischer JR. Ureteral stents and retrograde studies: a primer for the gynecologist. Curr Opin Obstet Gynecol 2009;21:434-41.

30. Joshi HB, Stainthorpe A, MacDonagh RP, et al. Indwelling ureteral stents: evaluation of symptoms, quality of life and utility. J Urol 2003;169:1065-9; discussion 1069.

31. Dyer RB, Chen MY, Zagoria RJ, et al. Complications of ureteral stent placement. Radiographics 2002;22:1005-22.

32. Lennon GM, Thornhill JA, Sweeney PA, et al. 'Firm' versus 'soft' double pigtail ureteric stents: a randomised blind comparative trial. Eur Urol 1995;28:1-5.

33. Thomas R. Indwelling ureteral stents: impact of material and shape on patient comfort. J Endourol 1993;7:137-40.

34. Angulo J, Cuevas P, Fernández A, et al. Tadalafil enhances the inhibitory effects of tamsulosin on neurogenic contractions of human prostate and bladder neck. J Sex Med 2012;9:2293-306. 
35. Joshi HB, Stainthorpe A, Keeley FX Jr, et al. Indwelling ureteral stents: evaluation of quality of life to aid outcome analysis. J Endourol 2001;15:151-4.

36. Miyaoka R, Monga M. Ureteral stent discomfort: etiology and management. Indian J Urol 2009;25:455-60.

37. Sharma G, Sharma AP, Mavuduru RS, et al. Role of phosphodiesterase inhibitors in stent-related symptoms:

Cite this article as: Zhang D, Sun K, Wang T, Wu G, Wang J, Wu J, Ma J, Cui Y. A meta-analysis of efficacy and safety of PDE5 inhibitors in the treatment of ureteral stent-related symptoms. Ann Palliat Med 2021;10(2):1000-1011. doi: 10.21037/ apm-20-1100 a systematic review and meta-analysis. World J Urol 2020;38:929-38.

38. Nestler S, Witte B, Schilchegger L, et al. Size does matter: ureteral stents with a smaller diameter show advantages regarding urinary symptoms, pain levels and general health. World J Urol 2020;38:1059-63. 